\title{
Warty carcinoma of the uterine cervix: a virus-induced disease?
}

Angel Danchev Yordanov ${ }^{1}$, Ivan Ivanov², Tereza Dineva ${ }^{3}$, Stanislav Slavchev ${ }^{4}$, Stoyan Kostov ${ }^{4}$, Strahil Strashilov ${ }^{5}$, Assia Konsoulova ${ }^{6}$

\author{
${ }^{1}$ Department of Gynaecological Oncology, Medical University Pleven, Pleven, Bulgaria \\ ${ }^{2}$ Department of General and Clinical Pathology, Medical University Pleven, Pleven, \\ Bulgaria \\ ${ }^{3}$ Scientific Laboratory, Department of Epidemiology, Medical University Pleven, Pleven, \\ Bulgaria \\ ${ }^{4}$ Department of Gynaecology, Medical University Varna, Varna, Bulgaria \\ ${ }^{5}$ Department of Plastic and Reconstructive Surgery, MU-Pleven, Pleven, Bulgaria \\ ${ }^{6}$ Complex Oncological Centre Burgas, Burgas, Bulgaria
}

Submitted: 20 May 2020; Accepted: 4 July 2020

Online publication: 6 August 2020

Arch Med Sci 2022; 18 (5): 1248-1252

DOI: https://doi.org/10.5114/aoms.2020.97997

Copyright @ 2020 Termedia \& Banach

\section{Abstract}

Introduction: Warty carcinoma (WC) of the uterine cervix is a rare subtype of squamous-cell carcinoma (SCC), and its frequency, clinical behaviour, and aetiology are obscure. It originates from condylomas, and a viral carcinogenesis seems logical.

Material and methods: Retrospective analysis was performed of all cervical carcinomas (CC), diagnosed at a single institution for a 10-year period. Analysed patients had stage I carcinoma. Patients with WC were identified, and their tumour samples were tested for high-risk HPV (hr-HPV) and EBV, using PCR and ISH. Clinical characteristics and WC rates across all stage I CC patients were assessed. All patients had minimum 3-year follow-up, and overall survival (OS) and 5-year survival rates were calculated.

Results: WC comprised $2.2 \%$ of all stage I CC $(n=630)$. The mean age of the patients was 48 years (range: 29-72). The primary tumour size was $2 \mathrm{~cm}$ in $4(28.6 \%)$ patients, $2-4 \mathrm{~cm}$ in $2(14.3 \%)$ patients, and $4 \mathrm{~cm}$ in $8(57.1 \%)$ patients. Lymph node metastasis was found in $1(7.1 \%)$ patient. EBV or hr-HPV were detected in $2(18.2 \%)$ patients using ISH, with no coinfection reported. $\mathrm{Hr}$-HPV was detected in $2(18.2 \%)$ patients; EBV in 4 (36.4\%) cases, and in 2 of them $(18.2 \%)$ there was a co-infection. Thirteen patients had a follow-up of $\geq 5$ years and their 5 -year OS was $100 \%$.

Conclusions: WC is a rare subtype of SCC with good prognosis, regardless of viral status. In contrast to SCC, its aetiology is not related to hr-HPV. The role of EBV remains unclear and cannot currently be denied.

Key words: aetiology, in situ hybridisation, polymerase chain reaction, human papillomavirus, Epstein-Barr virus, warty carcinoma.

\section{Introduction}

Cervical carcinoma is the fourth most common cancer in women [1]. Its genesis is commonly associated with human papillomavirus (HPV), human herpesvirus II, and cytomegalovirus [2]. HPV infections are considered to be primarily responsible for the disease [3-5]. Increasingly, more authors focus on Epstein-Barr virus (EBV) as a player in the onco-

\author{
Corresponding author: \\ Angel Danchev Yordanov PhD \\ Department of \\ Gynaecological Oncology \\ Medical University Pleven \\ Pleven, Bulgaria \\ E-mail: angel.jordanov@ \\ gmail.com
}


genesis of carcinoma of the cervix [6, 7]. Until now no definite aetiological factor has been identified.

Histologically, cervical carcinomas are classified into squamous cell carcinomas (SCC), adenocarcinomas, and adenosquamous carcinomas. SCC are the most frequent histological type - in 90 to $95 \%$ of the cases [8], which is further subdivided into subtypes, one of which is warty carcinoma [9]. Data about this subtype in the literature is scarce, and low-risk types of HPV are discussed in relation to its occurrence [10]. A viral co-infection (high-risk HPV (hr-HPV) and EBV) is implicated in the oncogenesis of SCC in general [11]; it is speculated that this co-infection could be a poor prognostic factor [12].

Our study aims to assess the incidence of hrHPV and/or EBV infection in patients with warty carcinoma of the uterine cervix via two different methodologies: in situ hybridisation (ISH) and polymerase chain reaction (PCR). If hr-HPV is not implicated in the aetiology of warty carcinoma, further larger tests of more rare and low-risk subtypes of HPV may be justified.

\section{Material and methods}

We performed a retrospective analysis of all cases of warty carcinoma of the uterine cervix, treated initially with surgery at the Gynaecologic Oncology Clinic, University Hospital, Pleven, Bulgaria. Data were collected for a 10-year period (Jan 2009-Dec 2016); the analysed cohort of patients included clinical stage I carcinoma of the cervix, i.e. the patients who were initially referred to surgery. The date of the last follow-up was December 2019. Clinical data were extracted from the medical records and patient's files. Prior to study inclusion, identified cases with warty carcinoma were subjected to a mandatory histology revision and confirmation of the histological diagnosis by a dedicated histopathologist. Pathological and clinical staging was defined as per TNM classification or FIGO staging. We analysed the clinical characteristics of the patients with warty carcinoma and calculated the rate of warty carcinoma. We assessed overall survival (OS) rate and calculated 5-year survival. To search for viral infections, slides from the paraffin-embedded tissues were tested for hr-HPV and EBV infection using two methodologies for viral DNA assessment: chromogenic ISH and real-time PCR. Statistical analysis was done with SPSS for Windows.

\section{Chromogenic in situ hybridisation}

Chromogenic in situ hybridisation (CISH) testing for EBV was done manually, using a ZytoFast EBV Probe (ZytoVision) for detection of Epstein-Barr (EBV) RNA in paraffin-embedded tissues, and the ZytoFast Plus CISH Implementation
Kit HRP-DAB (ZytoVision). Specimen pretreatment (e.g. dewaxing, proteolysis, etc.) and further processing was performed as per instructions provided by the manufacturer. Enzyme reaction with chromogenic substrates led to the formation of coloured precipitates. Hybridised probe fragments were visualized by light microscopy after nuclei dye counterstaining. Patients were tested for HRHPV DNA using a Ventana Benchmark Autostainer with a commercial kit (Inform HPV III family 16 trials [B] recognising HPV 16, 18, 31, 33, 35, 39, 45, $51,52,56,58$, and 66 subtypes) and ISH iVIEW Blue Plus Detection Kit.

\section{Real-time PCR}

EBV- and HPV-DNA in all extracted DNA samples were tracked by Amplisens EBV-screen/ monitor-FRT PCR kit and the AmpliSens HPV HCR genotype-FRT PCR kit (HR HVP 16, 18, 31, 33, 35, $39,45,51,52,56,58,59)$, respectively (Ecoli s.r.o., Slovak republic). Preparation of the PCR reaction mixture and PCR cycling parameters were as per instructions of the manufacturer. The $\beta$-globin gene served as an internal endogenous control. The PikoReal 96 Real-Time PCR System (Thermo Scientific, USA) was used for DNA amplification and detection of fluorescent dyes. Reactions were considered valid only if no PCR products were found in the negative control.

\section{Results}

In 630 patients with stage I cervical carcinoma were identified. Fourteen patients were diagnosed with warty carcinoma, which represented $2.2 \%$ of all cases of stage I cervical carcinoma. Three of the cases were excluded from the study due to material exhaustion and inability to conduct further tests.

The mean age of patients diagnosed with warty carcinoma was 48 years (range: 29-72 years). Six $(42.9 \%)$ patients had FIGO stage IB1, and $8(57.1 \%)$ patients had FIGO stage IB2 disease. In $4(28.6 \%)$ patients the primary tumour size was $<2 \mathrm{~cm}$, and in $8(57.1 \%)$ patients the primary tumour size was $>4 \mathrm{~cm}$. Metastatic lymph nodes were present in only 1 (7.1\%) patient. One patient died 113 months after the diagnosis due to a non-cancer-related reason. The 5-year survival rate was $100 \%$ in 13 patients with 5 -year follow-up (92.9\%). Table I summarises some clinical and pathoanatomical characteristics of the patients.

Eleven cases were tested for viral DNA, using ISH and rt-PCR. Either EBV or hr-HPV were detected in $2(18.2 \%)$ patients using ISH (Figures 1 and 2). There was no co-infection detected with ISH. PCR detected hr-HPV in 2 (18.2\%) and EBV in 4 (36.4\%) patients, with 2 of the cases being a co-infection 
Table I. Clinical and pathoanatomical characteristics of the patients

\begin{tabular}{|c|c|c|c|c|c|c|c|c|}
\hline \multirow[t]{2}{*}{ Case } & \multirow[t]{2}{*}{ Age } & \multirow{2}{*}{$\begin{array}{l}\text { Tumour size } \\
{[\mathrm{cm}]}\end{array}$} & \multirow[t]{2}{*}{ LN metastasis } & \multicolumn{2}{|c|}{ ISH } & \multicolumn{2}{|c|}{ PCR } & \multirow[t]{2}{*}{ Outcome } \\
\hline & & & & HPV & EBV & HPV & EBV & \\
\hline 1 & 50 & $<2$ & Negative & - & - & - & - & Alive at $46^{\text {th }}$ month \\
\hline 2 & 54 & $<2$ & Negative & + & - & + & + & Died at $113^{\text {th }}$ month \\
\hline 3 & 30 & $>4$ & Negative & - & - & - & - & Alive at $130^{\text {th }}$ month \\
\hline 4 & 29 & $>4$ & Negative & - & - & - & - & Alive at $127^{\text {th }}$ month \\
\hline 5 & 40 & $\mathrm{~B} / \mathrm{n} 2$ and 4 & Negative & - & - & - & - & Alive at $115^{\text {th }}$ month \\
\hline 6 & 42 & $>4$ & Negative & - & - & - & + & Alive at $93^{\text {rd }}$ month \\
\hline 7 & 45 & $>4$ & Positive & - & - & - & - & Alive at $90^{\text {th }}$ month \\
\hline 8 & 56 & $<2$ & Negative & - & - & - & - & Alive at $88^{\text {th }}$ month \\
\hline 9 & 72 & $>4$ & Negative & - & + & + & + & Alive at $70^{\text {th }}$ month \\
\hline 10 & 38 & $<2$ & Negative & - & - & - & - & Alive at $69^{\text {th }}$ month \\
\hline 11 & 63 & $\mathrm{~B} / \mathrm{n} 2$ and 4 & Negative & - & - & - & + & Alive at $60^{\text {th }}$ month \\
\hline 12 & 55 & $>4$ & Negative & NA & NA & NA & NA & Alive at $60^{\text {th }}$ month \\
\hline 13 & 49 & $>4$ & Negative & NA & NA & NA & NA & Alive at $140^{\text {th }}$ month \\
\hline 14 & 63 & $>4$ & Negative & NA & NA & NA & NA & Alive at $94^{\text {th }}$ month \\
\hline
\end{tabular}

ISH - in situ hybridisation, $P C R$ - polymerase chain reaction, HPV - human papillomavirus, EBV - Epstein-Barr virus.

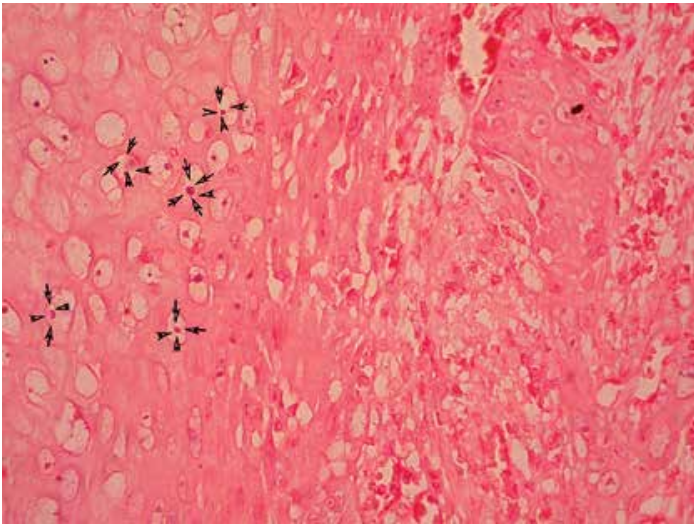

Figure 1. Signals produced by HPV probe in nuclei in warty carcinoma cases. ISH 400×

(18.2\%). PCR detected all ISH-positive for viral DNA via cases and additionally discovered four positive results (two for hr-HPV and two for EBV). These results are summarised in Table II.

\section{Discussion}

Warty carcinoma of the uterine cervix is a specific, rare subtype of squamous cell carcinoma. It

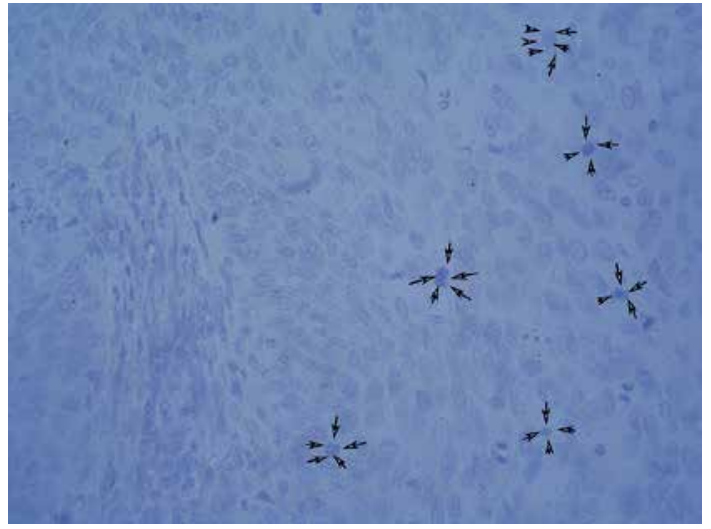

Figure 2. Signals produced by EBV probe in nuclei in warty carcinoma case. ISH 400x

is not well described in the literature. Its name "warty" describes the condylomatous features of the tumour with two parts: condyloma and invasive squamous cell carcinoma. Condylomas arise from normal epithelial tissue. Low-risk HPV types are considered relevant to the development of genital warts10, which are thought to be a precursor lesion of warty carcinoma. Originating

Table II. Positivity for EBV and HPV by methodology (PCR or ISH)

\begin{tabular}{|lccc|}
\hline Method & Positive for EBV only & Positive for hr-HPV only & Positive for both \\
\hline PCR & $36.4 \%$ & $18.2 \%$ & $18.2 \%$ \\
\hline ISH & $9.1 \%$ & $9.1 \%$ & - \\
\hline
\end{tabular}


from condylomas, it is logical to suspect a role for low-risk HPV in the aetiology of warty carcinoma, as well. But not all condylomas progress to warty carcinoma. The presence of koilocytes is a key feature of condylomas, which is preserved in warty carcinoma and may represent an indirect histological confirmation for the role of low-risk HPV. Histological parameters of warty carcinoma, besides the large number of koilocytes in the superficial and intermedia stratums of the epithelium, include biphasic pattern of a condylomatous and papillary configuration at the surface and SCC at the bottom. It appears that the malignant transformation of the foci is directly related to the condyloma [13]. However, another subtype of SCC - the verrucous carcinoma - represents malignant transformation with complete absence of koilocytes and hr-HPV aetiology [13]. Because the aetiology of SCC is in most cases related to HR-HPV, it is logical to assume that warty carcinoma is also potentially related to the same viruses. To the best of our knowledge, viral factors associated with the genesis of this carcinoma subtype have not been described until now.

Our cohort of patients was inconsistently positive for either EBV, HPV, or both. The rate of positivity for any of these infections by RT-PCR was 6 out of 22 tests (27.3\%). The numbers are too modest for any conclusions, but it seems that hr-HPV or EBV are not frequently detected. Additionally, the presence of koilocytes in both condylomas and warty carcinoma under microscope suggest the participation of low-risk HPV, which needs to be further assessed, probably via RT-PCR.

The role of EBV is even less clear. We detected EBV DNA in 4 (36.4\%) cases using PCR, and in half of them a co-infection with HPV was identified. Increasing evidence in the literature shows a potential association between EBV and cervical carcinoma, especially when coexisting with HPV $[14,15]$. Our results confirm that EBV alone or as a coinfection with HPV may be involved in the genesis of warty carcinoma.

As well as data about the aetiology of warty carcinoma, we also tried to describe some of its clinical features. All patients had stage I disease and were treated as per ESMO and NCCN guidelines for management of cervical warty carcinoma $[16,17]$. Radical hysterectomy with bilateral pelvic lymph dissection was the surgery of choice. An interesting observation was that patients with EBV viral infection had larger tumours $(>4 \mathrm{~cm}$ ), but the numbers are too small for any conclusions to be drawn. Another interesting finding is related to the prognosis of this subtype of SCC. Warty lesions are usually located only onsite within the cervix and do not infiltrate towards other anatomical structures. To the best of our knowledge, there are only exceptional cases of warty carcinoma in the literature where a paraovarian metastasis, a pouch of Douglas metastasis and right paratubal metastasis, or involvement of the uterine body [10] were described 18 . In our study group we observed a case of direct infiltration to the uterine body as well and a case of two micrometastases in pelvic lymph nodes. These were seen when the primary tumour exceeded $4 \mathrm{~cm}$, which is considered a risk factor for lymphogenous metastisation. No lymphovascular invasion was seen in any of the cases. The overall and relapse-free survival rates did not correlated with viral status or tumour size. As in the scientific literature, perimenopausal women are considered to be at higher risk [18], which was confirmed in our cohort, in which $45 \%$ of the patients were pre-menopausal.

In conclusion warty carcinoma of the uterine cervix is a specific, rare subtype of squamous cell carcinoma. It is associated with good prognosis and higher survival rates as compared to the same stage of the classic SCC. In contrast to classic SCC, high-risk HPV types are not involved in its genesis. However, the role of EBV remains unclear and cannot currently be denied. The role of lowrisk HPV should be further explored.

\section{Conflict of interest}

The authors declare no conflict of interest.

\section{References}

1. https://www.who.int/cancer/prevention/diagnosisscreening/cervical-cancer/en/ [accessed on 3 March 2020].

2. Qian YS, Lv W, Sui LH. Study on the relationship between genesis and development of cervical cancer and the infection of human papillomavirus type $16 / 18$, human herpesvirus II and cytomegalovirus. Zhonghua Liu Xing Bing Xue Za Zhi 2005; 26: 622-5.

3. Petry KU. HPV and cervical cancer. Scand I Clin Lab Invest Suppl 2014; 244: 59-62.

4. Turkler C, Kiremitli T. A retrospective analysis of women diagnosed with unclassified HPV genotypes. Arch Med Sci Civil Dis 2019; 4: 22-7.

5. Lewitowicz P, Nasierowska-Guttmejer A, Rokita W, et al. HPV genotyping and p16/Ki-67 test significantly improve detection rate of high-grade cervical squamous intraepithelial lesion. Arch Med Sci 2020; 16: 87-93.

6. Al Moustafa AE, Ahmed HG, Wulf G, Sultan AA. EBV-associated carcinomas: presence, role, and prevention strategies. Front Oncol 2018; 8: 528.

7. Vranic S, Cyprian FS, Akhtar S, Al Moustafa AE. The role of epstein-barr virus in cervical cancer: a brief update. Front Oncol 2018; 8: 113.

8. https://screening.iarc.fr/colpochap.php?lang=1\&chap=3 [accessed on 3 March 2020].

9. https://screening.iarc.fr/atlasclassifwho.php [accessed on 3 March 2020].

10. Kim HJ, Lee CM. p16-negative warty carcinoma of the uterine cervix with superficial invasion to the endometrium: a case report focusing on diagnostic pitfalls. Case Rep Clin Pathol 2017; 4: 12-5. 
11. Khenchouche A, Sadouki N, Boudriche A, et al. Human Papillomavirus and Epstein-Barr virus co-infection in cervical carcinoma in Algerian women. Virol J 2013; 10: 340.

12. Shi Y, Peng SL, Yang LF, et al. Co-infection of Epstein-Barr virus and human papillomavirus in human tumorigenesis Chin J Cancer 2016; 35: 16.

13. Cho NH, Joo HJ, Ahn HJ, Jung WH, Lee KG. Detection of human papillomavirus in warty carcinoma of the uterine cervix: comparison of immunohistochemistry, in situ hybridization and in situ polymerase chain reaction methods. Pathol Res Pract 1998; 194: 713-20.

14. Abudoukadeer A, Niyazi M, Aikula A, et al. Association of EBV and HPV co-infection with the development of cervical cancer in ethnic Uyghur women. Eur J Gynaecol Oncol 2015; 36: 546-50.

15. Vranic S, Cyprian FS, Akhtar S, Al Moustafa AE. The role of Epstein-Barr virus in cervical cancer: a brief update. Front Oncol 2018; 8: 113

16. https://www.esmo.org/Guidelines [accessed on 3 March 2020].

17. https://www.nccn.org/professionals/physician_gls/default.aspx [accessed on 3 March 2020].

18. Padberg BC, Bode B, Zimmermann D. Metastatic warty (condylomatous) carcinoma of the uterine cervix associated with low-risk HPV type 6. J Clin Cytol Cytopathol Acta Cytol 2006; 50: 235-8. 